\title{
Estudos Geoelétricos Com o Método TDEM por Meio da Técnica de Tx-Fixo e Rx-Móvel Aplicados à Exploração de Àgua Subterrânea na Bacia do Paraná
}

\author{
Gabriela Serejo, IAG/USP, Jorge Luis Porsani, IAG/USP, Julian David Realpe Campaña IAG/USP, Cassiano Bortolozzo
} IAG/USP

Copyright 2016, SBG - Sociedade Brasileira de Geofísica

Este texto foi preparado para a apresentação no VII Simpósio Brasileiro de Geofísica, Ouro Preto, 25 a 27 de outubro de 2016. Seu conteúdo foi revisado pelo Comitê Técnico do VII SimBGf, mas não ou parcial deste material para propósitos comerciais sem prévia autorização da SBGt.

\section{Abstract}

In this research we used the electromagnetic methods in the time domain (TDEM) and resistivity aimed at mapping of sedimentary and crystalline aquifers in the sedimentary basin. Data were acquired through fixed transmitter loop technique and a 3D-mobile coil receiver, also known as fixed-loop technique and vertical electrical sounding (VES). The data of the component-Bz of the magnetic field was inverted individually and then laterally interpolated to obtain a pseudo $2-D$ profile. The results permit to map of the shallow sedimentary aquifer (Fm. Adamantina) and the Cristalline aquifer (Fm. Serra Geral).

\section{Introdução}

Atualmente, a Terra vem passando por uma série de transformações globais. Estas transformações estão afetando o abastecimento de água na cidade de São Paulo, bem como em vários municípios localizados no interior do Estado. A crise hídrica impulsionou as pesquisas relacionadas à procura por água especialmente em aquíferos sedimentares rasos, onde poços podem ser perfurados com maior facilidade, mas também em aquíferos cristalinos profundos.

Os métodos geofísicos podem contribuir na procura de novos pontos para a exploração de água. Dentre eles os métodos eletromagnéticos são os mais utilizados, devido às informações da distribuição das resistividades elétricas do solo e a sua ampla profundidade de penetração. Através desses métodos é possível obter um modelo de resistividade elétrica em função da profundidade que pode ser associado a um determinado modelo geológico.

Em termos de sensibilidade, os métodos eletromagnéticos e geoelétricos são complementares. A SEV define melhor as estruturas mais rasas e resistivas e o TDEM define bem as estruturas mais profundas e condutivas (Schmutz et al., 2000). Logo, a integração dos dois métodos reduz as ambiguidades inerentes à interpretação dos resultados.

Nesta pesquisa os principais objetivos são mapear a estratigrafia geoelétrica da bacia do Paraná, visando determinar a espessura das camadas sedimentares (aquífero sedimentar raso) e localizar zonas de fraturas dentro da camada de basaltos (aquífero cristalino).

\section{Área de Estudo}

Os estudos foram realizados no município de lbirá, localizado na região ao noroeste do Estado de São Paulo, pertencente à Microrregião de São José do Rio Preto.

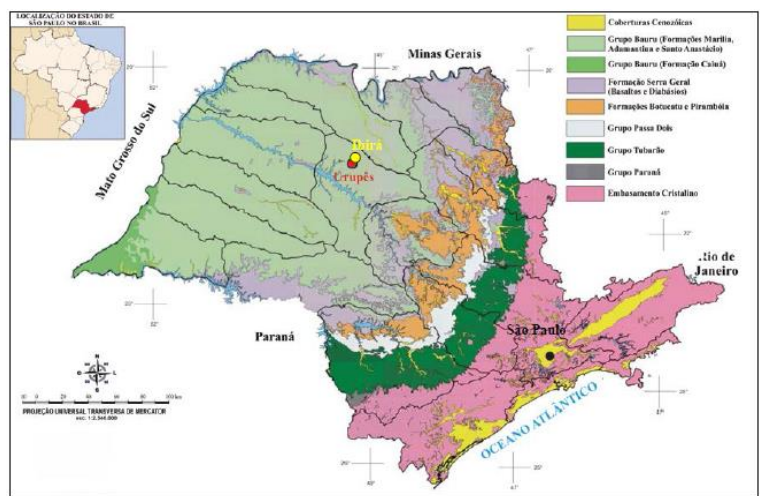

Figura 1: Distribuição da Bacia do Paraná no Estado de São Paulo e localização do município de lbirá. (Adaptado de Cônego Jr., 2012).

A região de lbirá encontra-se localizada sobre a Bacia Sedimentar do Paraná de acordo com Milani et al. (2007). A Bacia do Paraná é uma típica bacia intracratônica, com cerca de $1.500 .000 \mathrm{Km}^{2}$ de área, ou seja, uma ampla região sedimentar que compreende os territórios do Brasil meridional, Paraguai oriental, nordeste Argentino e norte Uruguaio, com orientação norte-sul e formato ovalado.

Nesta pesquisa, a área de estudo está restrita às Supersequências Gondwana III e Bauru. Esta restrição está associada ao objetivo do trabalho e os limites técnicos do equipamento TDEM.

A Supersequência Gondwana III, com idade do Jurássico Superior ao Cretáceo Superior, compreende os sedimentos eólicos da Formação Botucatu e os magmatitos da Formação Serra Geral.

Já a Supersequência Bauru tem espessura máxima de $300 \mathrm{~m}$, pertence ao Cretáceo e ocorre na porção norte da Bacia. Seu contato basal é discordante, sobretudo com basaltos da Formação Serra Geral. Ela é formada pelos grupos Caiuá e Bauru. Os dois grupos são formados essencialmente por arenitos.

Em Termas de lbirá, somente os arenitos do grupo Bauru tem ocorrência. 


\section{Metodologia/ Problema Investigado}

O método TDEM surgiu da necessidade de investigar alvos em profundidade e em locais com resistividade muito baixa. Sua vantagem em relação aos métodos eletromagnéticos no domínio da frequência é que as medidas são realizadas na ausência do magnético primário.

Assim como na sondagem elétrica vertical, o TDEM também é usado para se obter a variação da resistividade elétrica em função da profundidade (McNeill, 1980). Entretanto, para obtenção deste parâmetro são utilizados um loop transmissor e uma bobina receptora. Uma corrente elétrica contínua é injetada no loop de forma quadrada ou retangular. Segundo a Lei de Ampère

$$
\oint_{C} \vec{B} \cdot \overrightarrow{d l}=\iint_{S} \mu_{0} \cdot \vec{\jmath} \cdot \vec{n} \cdot d S
$$

toda corrente elétrica possui um campo magnético associado. No entanto, esse campo não induz correntes elétricas no substrato, pois é constante. Para que correntes elétricas sejam induzidas em subsuperfície é necessário provocar uma variação do campo magnético. Logo, a corrente elétrica é interrompida por um breve período de tempo (Turn-off) fazendo assim com que o campo magnético varie no tempo.

Segundo a Lei de Faraday, uma variação do campo eletromagnético no tempo induz uma força eletromotriz (FEM) transiente num circuito receptor (bobina receptora) no qual ele está agindo.

$$
\int_{C} \vec{E} \cdot \overrightarrow{d l}=\iint_{S}\left(-\frac{\partial B}{\partial t}\right) \cdot \vec{n} \cdot d S
$$

Como a dissipação do campo secundário varia conforme a resistência elétrica do condutor em subsuperfície é possível obter as propriedades geoelétricas dos materiais abaixo do arranjo. Todo o processo descrito acima é resumido na figura abaixo:

a)

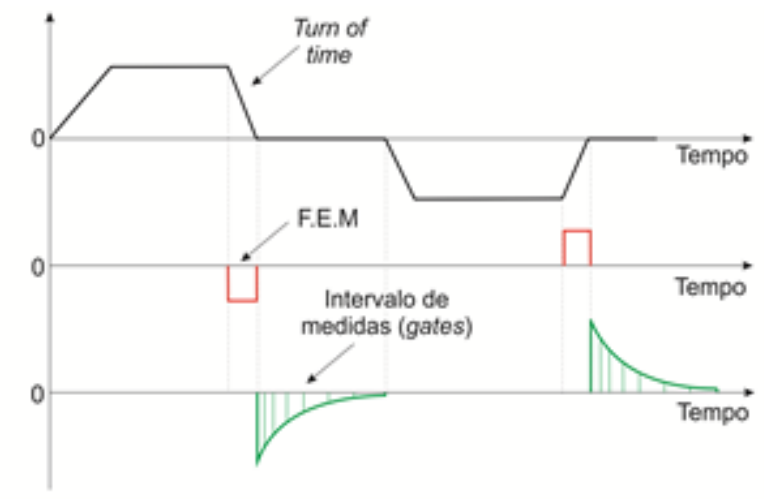

Figura 2: Diagrama da sequência de eventos de um levantamento TDEM (Adaptado de Bortolozzo, 2015).

\section{Aquisição dos Dados}

Duas campanhas foram realizadas para aquisição dos dados, a primeira em outubro e a segunda em novembro de 2014.

$\mathrm{Na}$ aquisição dos dados TDEM foram utilizados o transmissor TEM57-MK2, o receptor PROTEM e a bobina receptora 3D com área efetiva de $200 \mathrm{~m}^{2}$, todos os equipamentos fabricados pela empresa canadense Geonics. O receptor PROTEM possui 20 gates de aquisição e permite adquirir dados nas frequências 30 $\mathrm{Hz}, 7,5 \mathrm{~Hz}$ e $3 \mathrm{~Hz}$, o que permite 3 níveis de investigação. A fonte de injeção de corrente elétrica empregada foi um gerador à gasolina de potência de 2Kv-A fabricado pela Honda.

Os dados foram adquiridos por meio da técnica de loop transmissor (Tx) fixo e bobina receptora (Rx) 3D móvel, também conhecida como técnica fixed-loop.

Os arranjos de campo utilizados foram loop central e fixed-loop. O loop central possui 200×200 m de área.

Além dos dados do método TDEM também foi empregado o método da Eletrorresistividade. Uma sondagem elétrica vertical foi realizada no centro do loop central com abertura total de $1000 \mathrm{~m}(\mathrm{AB} / 2=500)$.

O caminhamento TDEM possui comprimento total de $1000 \mathrm{~m}$. Cada sondagem TDEM possui um espaçamento de $25 \mathrm{~m}$. Neste trabalho, apenas as sondagens dentro do loop central de $200 \mathrm{~m}$ de lado foram processadas e interpretadas, pois os dados são geralmente mais claros já que o campo magnético é mais intenso nas proximidades da fonte transmissora. Fora do loop, o campo magnético apresenta valores negativos, devido à orientação do campo secundário gerado pelas correntes de Focault. A transição entre valores de voltagem positivos e negativos da componente $z$ do campo criam uma região com valores de resistividade muito altos e de difícil ajuste para o algoritmo de inversão (Campaña, 2015).

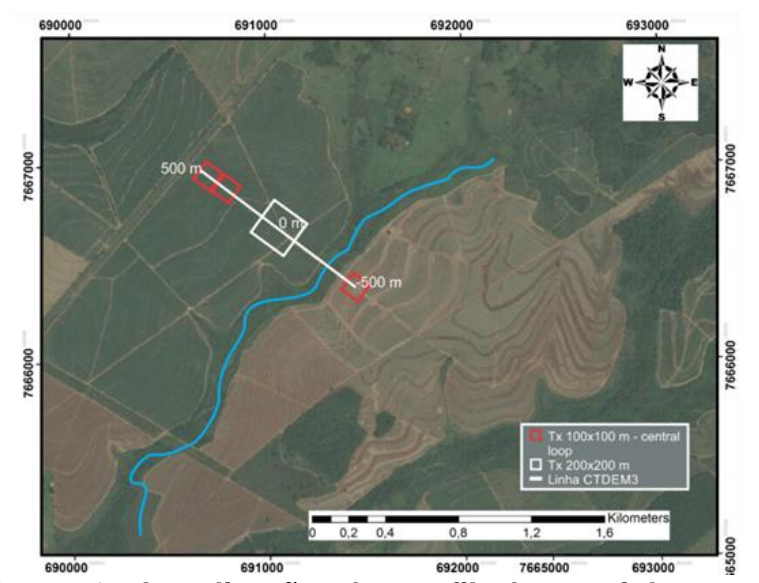

Figura 3: Localização do perfil de caminhamento TDEM na região de Termas de lbirá representado pela linha branca. (Adaptado de Campaña, 2015). 


\section{Resultados/ Interpretação}

Os dados foram processados e invertidos por meio do software IX1D (Interpex, Ltd). O processo de inversão consiste em determinar os parâmetros físicos resistividade e espessura do interior da Terra a partir dos dados observados.

Antes do processamento os dados foram editados. A edição dos dados basicamente consistiu na remoção de pontos espúrios, ruidosos e saturados. Todos os pontos com frequência de $3 \mathrm{~Hz}$ foram excluídos, pois apresentaram uma tendência linear nos últimos pontos da curva de resistividade aparente, indicando a presença do efeito superparamagnético, como mostrado nos estudos de Kozhenikov \& Antonov (2008) e Campaña (2015).

O processo de inversão começou pela geração de um modelo de camadas ou variações suaves chamado inversão de Occam (Constable et al., 1987), que faz uma estimativa das resistividades e espessuras das camadas em subsuperfície, gerando um perfil de resistividade contínuo para a Terra e assim cria um número elevado de camadas discretas. O resultado foi um modelo de quatro camadas, porém com RMS de ajuste alto. Para melhorar o valor de RMS um segundo modelo foi testado, desta vez sem variações suaves, o que resultou em um modelo de inversão de cinco camadas, mostrando uma região condutiva que não foi mostrada na inversão de Occam e com um RMS de ajuste menor que $5 \%$, o que é considerado pela literatura como satisfatório.

A figura 3 representa o resultado da inversão dos dados para sondagem de posição $550 \mathrm{~m}$ do perfil. A curva da esquerda mostra o resultado da resistividade aparente em função do tempo. Já o modelo geoelétrico é mostrado na figura da direita, onde 0 eixo $x$ representa $a$ resistividade e o eixo y representa a profundidade.
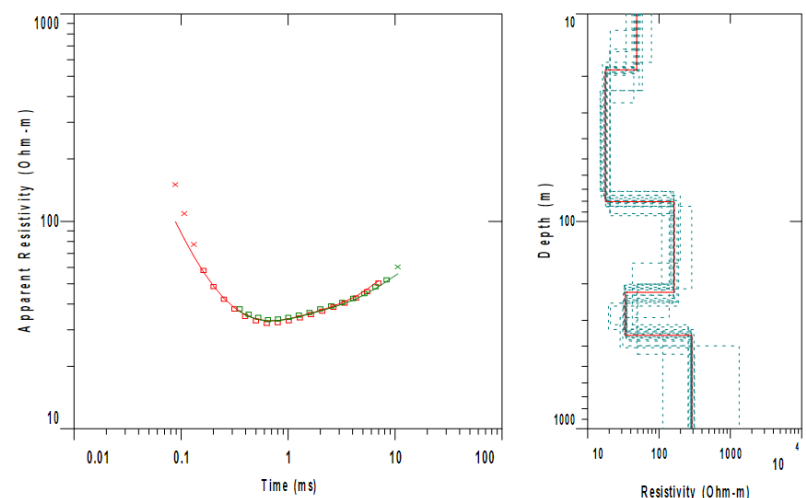

Figura 3: Resultado da inversão para sondagem TDEM na posição $550 \mathrm{~m}$

A partir de aproximadamente $250 \mathrm{~m}$, os modelos equivalentes possuem um espalhamento maior, devido a perca de resolução com a profundidade do método, dificultando assim o processo de inversão. Já as camadas mais rasas possuem um ajuste melhor aos modelos equivalentes (linhas tracejadas na figura da direita).
A primeira camada superficial é moderadamente resistiva, com valores entre 30 e 100 Ohm.m de resistividade e 10 a $15 \mathrm{~m}$ de espessura e está associada aos arenitos não saturados da Formação Adamantina. A segunda camada, bastante condutiva, possui valores de 10 a 20 Ohm.m e espessura entre 30 a 50 m e está associada aos arenitos saturados da Formação Adamantina. Já a terceira camada, moderadamente resistiva, com valores médios de 100 ohm.m e $100 \mathrm{~m}$ de espessura esta associada aos basaltos da Formação Serra Geral. A quarta camada, condutiva, possui valores médios de 30 ohm.m e $150 \mathrm{~m}$ de espessura e está relacionada aos basaltos fraturados preenchidos com água da Formação Serra Geral. A quinta camada possui valores altos de resistividade, variando entre 400 e 700 ohm.m e está associada aos basaltos da Formação Serra Geral.

A segunda camada, com alta condutividade pode ser interpretada como o aquífero sedimentar raso Bauru.

Como se pôde observar, as camadas de basalto tiveram valores relativamente baixos de resistividade. Foram detectadas três camadas constituídas por basalto. A primeira com valores médios de $100 \mathrm{ohm} . \mathrm{m}$, a segunda com $30 \mathrm{ohm} . \mathrm{m}$ e a terceira com $600 \mathrm{ohm} . \mathrm{m}$. A primeira camada pode estar associada a um basalto pouco fraturado, o que explicaria os valores baixos de resistividade, ou também a variação da geometria das fraturas da segunda camada que é condutiva, poderia influenciar nos valores de resistividade da primeira camada. Esta camada condutiva esta associada ao aquífero cristalino Serra Geral. Já a terceira camada possui valores maiores de resistividade e poderia ser interpretada como basalto são.

A figura 4 representa o perfil pseudo-2D criado a partir da interpolação dos modelos invertidos individualmente do caminhamento TDEM entre as posições 400 e $600 \mathrm{~m}$ da linha de $1000 \mathrm{~m}$.

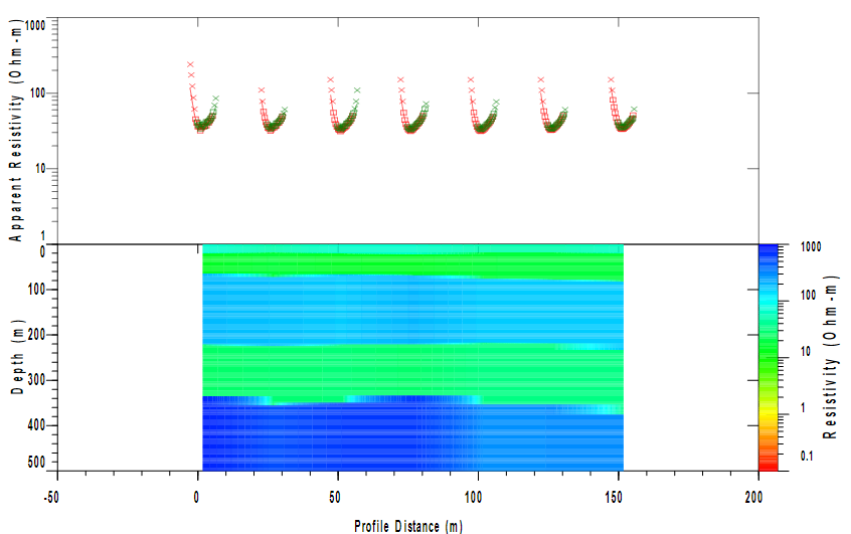

Figura 4: Perfil pseudo-2D

Todas as sondagens processadas estão representadas na parte de cima da figura 4 e abaixo delas é representado o perfil pseudo-2D. Cada camada foi definida em subsuperfície assim como suas variações e espessuras. Pôde-se observar que todas as sondagens 
convergiram para um modelo de camadas compatível com a geologia da região.

\section{Conclusão}

De modo geral, o processo de inversão 1D permitiu a geração de perfis geoelétricos compatíveis com a geologia da área de estudo. O perfil pseudo-2D auxiliou na compreensão da distribuição das camadas e em suas espessuras em subsuperfície.

$\mathrm{O}$ aquífero sedimentar raso Bauru foi bem definido com espessura de aproximadamente $30 \mathrm{~m}$. Já a espessura do aquífero cristalino Serra Geral varia bastante, cerca de 80 $\mathrm{m}$ a $150 \mathrm{~m}$ devido a perca de resolução do método com o aumento da profundidade.

Os resultados encontrados mostram a versatilidade do método TDEM, sendo uma ferramenta importante para busca de novas fontes de água, diante da crise hídrica em São Paulo. Além disso, os resultados são de grande importância para região de Termas de Ibirá, já que a exploração de águas em grandes profundidades, mais precisamente no aquífero cristalino Serra Geral, foi melhor compreendida e pode ser explorada.

\section{Agradecimentos}

Gabriela Serejo de Oliveira agradece ao CNPq pela bolsa de pesquisa de IC (151906/2015-7). Jorge Luis Porsani agradece a FAPESP (2012/15338-4) e ao CNPq (406653/2013-5 e 301692/2013-0) pelo apoio ao Projeto de Pesquisa. Cassiano Antonio Bortolozzo agradece a FAPESP (2011/06404-0) pela bolsa de pesquisa. Julian David Realpe Campaña agradece a CAPES pela bolsa de pesquisa. Á USP pela infraestrutura e aos colegas, Marcelo, Ernande, Emerson, Vinicius, Marcão, Luciana, e outros pela ajuda nos trabalhos de campo.

\section{Referências}

Bortolozo, C.A. Inversão conjunta 1d de dados de SEV e TDEM: Aplicações em hidrogeologia, dissertação de mestrado, IAG, Universidade de São Paulo, 2011.

Campaña, J. D. R., 2015. Mapeamento de aquíferos sedimentares e fraturados na Bacia do Paraná por meio da técnica de caminhamento TDEM, usando Tx-fixo e Rxmóvel. Dissertação de mestrado, IAG, Universidade de São Paulo.

Cônego Jr., D. Estudo Hidrogeológico na região de Urupês-SP por meio do Método Eletromagnético no Domínio do Tempo (TDEM). Trabalho de Graduação, IAG/USP, 2012.

Constable, S. C., Parker, R. L., Constable, C. G. Occam's inversion: A practical algorithm for generating smooth models from electromagnetic sounding data. Geophysics 52, 289-300, 1987.

Kozhevnikov, N. O., Antonov, E. Y. The magnetic relaxation effect on TEM responses of a uniform earth, Russian Geology and Geophysics 49, 197-205, 2008.

McNeill, J.D., 1980. Applications of transient electromagnetic techniques, Geonics Limited, technical note TN-7.

Milani, E., Melo, J., Souza, P., Fernandes, L., França, A. B. Bacia do Paraná. Boletim de Geociencias da Petrobrás, 15, No.1, 265-287. Rio de Janeiro, Brasil, 2007.

Schumutz, M. et al. Joint electrical and time domain electromagnetism (TDEM) data inversion applied to the Super Sauze earthflow (France), Surveys in Geophysics, v. 21, p. 371-390, 2000. 